\title{
Placental Lesions in Meconium Aspiration Syndrome
}

\author{
Binnari $\mathrm{Kim}^{1} \cdot$ Soo-young $\mathrm{Oh}^{2}$ \\ Jung-Sun Kim ${ }^{1,3}$ \\ Departments of ${ }^{1}$ Pathology and Translational \\ Genomics and ${ }^{2} \mathrm{Obstetrics}$ and Gynecology, \\ Samsung Medical Center, Sungkyunkwan \\ University School of Medicine, Seoul; \\ ${ }^{3}$ Department of Health Sciences and Technology, \\ Sungkyunkwan University, SAIHST, Seoul, Korea
}

Received: May 17, 2017

Revised: July 10, 2017

Accepted: July 20, 2017

\section{Corresponding Author}

Jung-Sun Kim, MD, PhD

Department of Pathology and Translational

Genomics, Samsung Medical Center,

Sungkyunkwan University School of Medicine,

81 Irwon-ro, Gangnam-gu, Seoul 06351, Korea

Tel: +82-2-3410-2767

Fax: +82-2-3410-0025

E-mail: jsunkim@skku.edu
Background: Meconium aspiration syndrome (MAS) is defined by respiratory distress requiring supplemental oxygen in a meconium-stained neonate. MAS is clinically subclassified as mild, moderate, and severe according to the oxygen requirement. The aims of this study were to compare the histological findings in the placentas of MAS neonates with those of meconium-stained but non-MAS neonates and to analyze the correlation between the severity of MAS and the grade of its histological parameters. Methods: We collected 160 singleton term placentas from neonates with meconium staining at birth from a tertiary medical center, Seoul, Republic of Korea. We reviewed hematoxylin and eosin sections of tissue samples (full-thickness placental disc, chorioamniotic membranes, and umbilical cord). Results: Funisitis was present more frequently in MAS than in non-MAS $(p<.01)$, of which the stage was correlated with the severity of MAS $(p<.001)$. The histological findings consistent with maternal underperfusion and chronic deciduitis were more frequent in MAS than in non-MAS $(p<.05)$. There was a correlation between the degree of chorionic vascular muscle necrosis and the severity of MAS $(p<.05)$. Conclusions: Our results suggest that fetal inflammatory response evidenced by funisitis occurs prenatally in MAS and that the stage of funisitis and of chorionic vascular muscle necrosis may be a predictive marker of the severity of MAS.

Key Words: Placenta; Meconium; Meconium aspiration syndrome; Chorioamnionitis; Chorionic vascular muscle necrosis
Meconium-stained neonates are quite common, accounting for about $10 \%$ to $16 \%$ of term pregnancies, in which a minority of cases suffer from respiratory distress requiring supplemental oxygen. ${ }^{1-4}$ These cases are called meconium aspiration syndrome (MAS), occurring in $2 \%$ to $36 \%$ of meconium-stained neonates. ${ }^{5,6}$ MAS is clinically subclassified as mild, moderate, and severe, according to the degree of respiratory distress and treatment requirements. In the past, the whole spectrum of MAS was considered as a group of diseases caused by meconium aspiration, but more recently it is understood that severe MAS is pathophysiologically different from mild and moderate MAS., ${ }^{5,7}$ The time and amount of meconium exposure are not correlated to the severity of MAS. ${ }^{8,9}$ The risk factors of severe MAS do not show a linear extension with those of mild and moderate MAS. ${ }^{7}$ Moreover, the histologic and physiologic changes in severe MAS cases cannot be explained by aspiration of meconium per se..$^{10,11}$ Rather, it is proposed that severe MAS results from chronic asphyxia or infection accompanying meconium passage and lung damage.

The placenta is an organ that connects the fetus to the uterus of the mother, thus providing the fetus with a safe environment ren- dering gas exchange and waste elimination. In a sense, the placenta is a unique organ that mirrors the status of a fetus and mother during pregnancy. For example, when the placental membranes are ruptured and amniotic fluid infection occurs, the placenta shows acute chorioamnionitis (as the maternal inflammatory response) and funisitis (as the fetal inflammatory response). ${ }^{12}$ When the placenta does not carry adequate oxygen and nutrition for the fetus due to maternal underperfusion such as preeclampsia, the placental villi show increased syncytial knots, villous agglutination, intervillous fibrin, and distal villous hypoplasia, while maternal vessels in the decidua disclose atherosis or mural hypertrophy of the arterioles. ${ }^{13}$ In contrast, the vascular thrombo-occlusion of a fetal origin is evidenced by avascular villi and villous stromal-vascular karyorrhexis accompanied by thrombus or intimal fibrin cushion of fetal vessels in the placenta. ${ }^{14}$ Meanwhile, meconium-laden macrophages in the placenta are usually considered to be indicators of the meconium passage in utero. ${ }^{15}$ In addition, acute chorioamnionitis, funisitis, chorionic vascular muscle necrosis, and amnion degeneration are accompanied by meconium exposure. ${ }^{16,17}$

MAS is one of the significant causes of neonatal respiratory 
distress leading to various morbidities and mortality. ${ }^{18,19}$ It is critical to know the risk factors of MAS, especially the severe one, as soon as possible before and/or after birth to manage a neonate predisposed to MAS. In order to find histopathological findings in the placenta to predict the occurrence and severity of MAS, we evaluated the histopathological findings in placentas from the MAS neonates, compared them with those from the meconium-stained but non-MAS neonates, and analyzed any correlation between the severity of MAS and the grade of the histological parameters.

\section{MATERIALS AND METHODS}

Among singleton term neonates with meconium staining at birth $(\mathrm{n}=835)$ from all live deliveries $(\mathrm{n}=16,264)$ in our institution from January 2006 to June 2014, a total of 160 cases whose placentas were available for histological examination were included in this retrospective study. The study was approved as a retrospective study without informed consent by the institutional review board of the hospital (2011-07-063). Multiple gestation, fetal deaths in utero, or other major anomalies were excluded. Clinical characteristics of the study population were reviewed in three categories: (1) maternal factors (age, parity, gestational age at delivery, mode of delivery); (2) neonatal factors (weight, sex, presence of fetal growth restriction, Apgar score, grade of meconium staining, neonatal intensive care unit admission and duration, arterial blood gas analysis of cord blood); and (3) intrapartum factors (presence of fever $\left[\geq 38^{\circ} \mathrm{C}\right]$, rupture of membrane to delivery interval, oligohydramnios, use of labor epidural anesthesia, use of oxytocin, and fetal heart rate patterns). MAS was classified as follows: mild, requiring $<40 \%$ oxygen for $<48$ hours; moderate, requiring $\geq 40 \%$ oxygen for at least 48 hours; or severe, requiring assisted mechanical ventilation for more than 48 hours. ${ }^{5,6}$

The tissue samples (the placental disc in full thickness, a cross section of the umbilical cord, and a roll of the chorioamniotic membranes) were fixed in $10 \%$ formalin and embedded in paraffin. The tissue sections stained with hematoxylin and eosin were reviewed by a pathologist who was blind to the clinical information. Placental histologic findings were categorized as those associated with amniotic fluid infection, maternal underperfusion, and fetal vascular obstructive lesions, according to the criteria proposed by the perinatal section of the Society for Pediatric Pathology. ${ }^{12-14}$ Chronic placental inflammation such as chronic villitis, chronic chorioamnionitis, and chronic deciduitis were diagnosed according to the criteria reported previously. ${ }^{14,20,21}$ Meconium-laden macrophages, amnion degeneration, chorionic vascular muscle necrosis were included as histological findings related to meconium staining (Fig. 1). ${ }^{15-17}$ Tables 1 and 2 summarize the histological findings and their grading systems (if included).

For statistical analysis, SPSS Statistics ver. 23 (IBM Corp., Armonk, NY, USA) was used. For evaluation of the significance of clinical variables in MAS, we used chi-square test and Fisher exact test for the proportions and Kruskal-Wallis test and MannWhitney $\mathrm{U}$ test for the continuous variables. The relationship between histologic findings and MAS was verified by chi-square test and Fisher exact test. For evaluation of the correlation between the grades of histopathologic findings and the severity of MAS, linear-by-linear-association was used. The p-values less than .05 were considered to be statistically significant.

\section{RESULTS}

\section{Clinical characteristics of meconium-stained neonates and the rate of MAS}

The number of singleton term neonates with meconium staining at birth was $835(5.13 \%)$ among all live neonates $(n=16,264)$ born in our institution from January 2006 to June 2014. MAS developed in 80 out of 835 (9.58\%) term neonates with meconium staining. Placentas were available in 160 meconium-stained neonates; 41 of 80 cases (51\%) with MAS; and 119 of 755 cases (15.7\%) without MAS. Thirty-three neonates had mild MAS, four had moderate MAS, and four had severe MAS. The clinical factors indicating neonatal morbidity including Apgar score (1 minute) $<4$, Apgar score $(5$ minutes $)<7$, severe meconium staining, neonatal intensive care unit admission of long duration, low cord $\mathrm{pH}$, cord base excess, and fetal tachycardia were detected more frequently in MAS group than in no MAS group. The clinical findings of 160 meconium-stained neonates are summarized in Table 3.

\section{Comparison of the histopathologic findings between MAS and non-MAS}

Among the findings associated with amniotic fluid infection, acute funisitis was more frequent in MAS than in non-MAS placentas $(65.9 \%$ [27/41] vs 39.5\% [47/119], $\mathrm{p}<.01)$. There was no significant difference in the frequency of acute chorioamnionitis between MAS and non-MAS placentas (58.5\% [24/41] vs $47.9 \%$ [57/119], $\mathrm{p}>.05)$. The findings associated with maternal underperfusion were detected more frequently in MAS placentas than in non-MAS placentas (31.7\% [13/41] vs 15.1\% [18/119], $\mathrm{p}<.05)$, but the frequency of the findings associated with fetal vascular thrombo-occlusive disease was not significantly different 

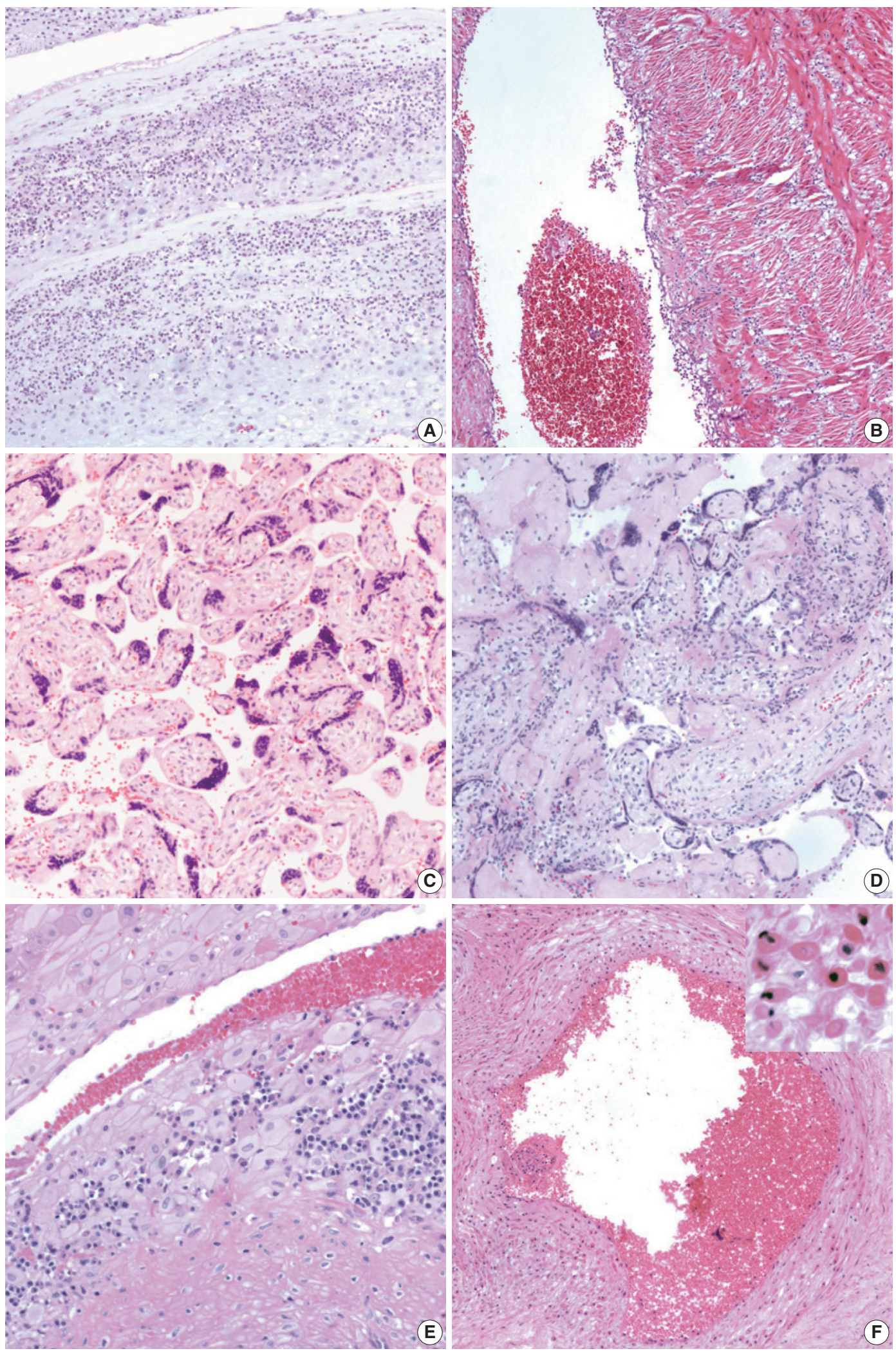

Fig. 1. Representative histological findings of the placenta. (A) Acute chorioamnionitis. (B) Funisitis. (C) Increased syncytial knots. (D) Chronic vilitis. (E) Chronic deciduitis. (F) Chorionic vascular muscle necrosis. 
Table 1. Histologic findings of placentas evaluated in this study

\begin{tabular}{l} 
Histologic finding \\
\hline Findings consistent with amniotic fluid infection \\
Acute chorioamnionitis \\
Funisitis \\
Findings consistent with maternal underperfusion \\
Remote villous infarct \\
Recent villous infarct \\
Increased syncytial knots \\
Villous agglutination \\
Increased intervillous fibrin \\
Distal villous hypoplasia \\
Persistent muscularization of basal plate arteries \\
Mural hypertrophy of decidual arterioles \\
Acute atherosis of basal plate arteries and/or decidual arterioles \\
Findings consistent with fetal vascular thrombo-occlusive disease \\
Villous changes (villous stromal-vascular karyorrhexis, hyalinized avascular \\
villi) \\
Thrombi, large fetal vessels \\
Intimal fibrin cushions, large fetal vessels \\
Fibromuscular sclerosis, intermediate-sized fetal vessels \\
Chronic inflammation \\
Chronic vilitis (VUE) with obliterative fetal vasculopathy \\
Chronic chorioamnionitis \\
Chronic deciduitis \\
Findings associated with meconium staining \\
Amnion degeneration \\
Meconium-laden macrophages \\
Chorionic vascular muscle necrosis \\
\hline
\end{tabular}

VUE, villitis of unknown etiology.

between MAS and non-MAS placentas $(0 \%$ [0/41] vs $7.6 \%$ [9/119], $\mathrm{p}>.05)$. Neither chronic villitis nor chronic chorioamnionitis was not increased in MAS placentas compared to nonMAS placentas (12.2\% [5/41] vs 5.9\% [7/119], 12.2\% [5/41] vs $7.6 \%$ [9/119], $\mathrm{p}>.05)$, whereas chronic deciduitis showed a higher frequency in MAS than in non-MAS cases $(7.3 \%$ [3/41] vs $0 \%[0 / 119], \mathrm{p}<.05)$. The frequencies of meconium-laden macrophages, amnion degeneration, and chorionic vascular muscle necrosis were not related to MAS $(95.1 \%$ [39/41] vs $96.6 \%$ [114/118], $91.3 \%$ [21/23] vs $97.3 \%$ [72/74], and $10.3 \%$ [4/39] vs $10.4 \%$ [11/106], respectively, $\mathrm{p}>.05$ ) (Fig. 2).

\section{Correlation between the severity of MAS and the grade of the placental histological findings}

We analyzed the correlation between the severity of MAS and the grade of pathological findings and found out that the grade of funisitis and that of chorionic vascular muscle necrosis were higher as the severity of MAS increased $(\mathrm{p}<.001$ and $\mathrm{p}<.05$, respectively). Other parameters including acute chorioamnionitis, maternal underperfusion, and meconium-laden macrophages did
Table 2. Histologic findings graded according to the severity

\begin{tabular}{ll}
\hline & Histologic finding \\
\hline Acute chorioamnionitis & 0: None \\
1: Acute subchorionitis or chorionitis & 2: Acute chorioamnionitis \\
3: Necrotizing chorioamnionitis or & subacute chorioamnionitis \\
0: None & \\
1: Umbilical phlebitis or chorionic \\
vasculitis \\
2: Umbilical arteritis \\
3: Concentric umbilical perivasculitis \\
0: None \\
1: The mean number of 10 fields \\
( $\times 200):<5$ \\
2: The mean number of 10 fields \\
( $\times 200): 5-20$ \\
3: The mean number of 10 fields \\
( $\times 200):>20$ \\
0: None \\
1: Necrosis of chorionic vessels \\
2: Necrosis of umbilical cord vessels \\
3: Necrosis of chorionic vessels and \\
umbilical cord vessels \\
0: None \\
1: One histologic finding of maternal \\
underperfusion \\
2: Two or three histologic findings of \\
maternal underperfusion \\
3: Four or more histologic findings of \\
maternal underperfusion
\end{tabular}

Meconium-laden macrophages were counted in membranes, chorionic plate, and umbilical cord respectively, of which the maximum score among these areas was chosen to evaluate the correlation with meconium aspiration syndrome.

not show any significant correlation with the severity of MAS (Fig. 3).

\section{DISCUSSION}

This study demonstrated that acute funisitis, histological findings associated with maternal underperfusion, and chronic deciduitis were frequently found in MAS. The grade of funisitis and chorionic vascular muscle necrosis was correlated with the severity of MAS.

Funisitis, which is characterized by the migration of polymorphonuclear leukocytes from the lumen to the wall of the umbilical vessels, was the most significant histological factor associated with MAS. ${ }^{12}$ Funisitis is most commonly associated with intraamniotic infection as is acute chorioamnionitis. Acute chorioamnionitis represents a maternal inflammatory response to intraamniotic infection, whereas funisitis is an evidence of a fetal inflammatory response and reflects a systemic fetal inflammatory response syndrome. ${ }^{22-28}$ Meconium may induce local inflammation following 
tissue degeneration in the fetal membranes (chorioamnionitis) and umbilical cord (funitis) by its leukotactic activity, but it is less severe than that by intraamniotic infection is. ${ }^{17}$ Intraamniotic inflammation occurs more frequently in meconium-stained amniotic fluid than in clear amniotic fluid. ${ }^{29-34}$ The significant association of funisitis with MAS but not acute chorioamnionitis, in spite of the presence of both acute chorioamnionitis and funisitis in intraamniotic infection/inflammation, suggests that a fetal inflammatory response is crucial to MAS but not a general intraamniotic inflammatory response. It has been proposed that the combination of a local inflammatory response in the lung by meconium and capillary damage/leakage as a manifestation of systemic fetal inflammatory

Table 3. Clinical characteristics in non-MAS and MAS groups

\begin{tabular}{|c|c|c|c|c|c|c|c|c|}
\hline \multirow[b]{2}{*}{ Clinical factor } & \multirow{2}{*}{$\begin{array}{c}\text { Non-MAS } \\
(n=119)\end{array}$} & \multicolumn{6}{|c|}{$\operatorname{MAS}(n=41)$} & \multirow{2}{*}{$\begin{array}{c}p^{-} \\
\text {value }^{d}\end{array}$} \\
\hline & & $\begin{array}{c}\text { Mild } \\
(n=33)\end{array}$ & $\begin{array}{c}p- \\
\text { value }^{\mathrm{a}}\end{array}$ & $\begin{array}{l}\text { Moderate } \\
(n=4)\end{array}$ & $\begin{array}{c}\mathrm{p}- \\
\text { value }^{b}\end{array}$ & $\begin{array}{l}\text { Severe } \\
(n=4)\end{array}$ & $\begin{array}{c}\mathrm{p}- \\
\text { value }^{\mathrm{c}}\end{array}$ & \\
\hline Age $(y r)^{e}$ & $\begin{array}{c}32 \\
(25 \text { to } 44)\end{array}$ & $\begin{array}{c}32 \\
\text { (24 to 37) }\end{array}$ & $>.05$ & $\begin{array}{c}34 \\
\text { (28 to } 36)\end{array}$ & $>.05$ & $\begin{array}{c}34 \\
\text { (26 to } 36)\end{array}$ & $>.05$ & $>.05$ \\
\hline Gestational age at delivery (wk) & $\begin{array}{c}40.2 \\
(37.2 \text { to } 41.5)\end{array}$ & $\begin{array}{c}40.3 \\
\text { (37.3 to 41.6) }\end{array}$ & $>.05$ & $\begin{array}{c}40.7 \\
\text { (39.5 to 41.4) }\end{array}$ & $>.05$ & $\begin{array}{c}39.1 \\
(38.2 \text { to } 40.1)\end{array}$ & $>.05$ & $>.05$ \\
\hline Primiparity (\%) & 88 & 94 & $>.05$ & 75 & $>.05$ & 75 & $>.05$ & $>.05$ \\
\hline \multicolumn{9}{|l|}{ Mode of delivery } \\
\hline Elective C/S (\%) & 1.7 & 0 & $>.05$ & 0 & $>.05$ & 0 & $>.05$ & $>.05$ \\
\hline Emergency C/S (\%) & 54.6 & 42 & & 75 & & 100 & & \\
\hline Vaginal (\%) & 43.7 & 58 & & 25 & & 0 & & \\
\hline \multicolumn{9}{|l|}{ Neonatal factor } \\
\hline Weight $(\mathrm{kg})^{e}$ & $\begin{array}{c}3.24 \\
(1.98 \text { to } 4.57)\end{array}$ & $\begin{array}{c}3.04 \\
(1.98 \text { to } 4.06)\end{array}$ & $>.05$ & $\begin{array}{c}3.09 \\
(2.91 \text { to } 3.56)\end{array}$ & $>.05$ & $\begin{array}{c}3.36 \\
(2.6 \text { to } 4.4)\end{array}$ & $>.05$ & $>.05$ \\
\hline Growth restriction <10p (\%) & 22 & 33 & $>.05$ & 0 & $>.05$ & 25 & $>.05$ & $>.05$ \\
\hline Apgar score (1 min) < $4(\%)$ & 3.3 & 45 & $<.001$ & 25 & $>.05$ & 50 & $<.05$ & $<.001$ \\
\hline Apgar score $(5 \mathrm{~min})<7(\%)$ & 0.8 & 24 & $<.001$ & 25 & $>.05$ & 50 & $<.01$ & $<.001$ \\
\hline \multicolumn{9}{|l|}{ Grade of meconium staining (\%) } \\
\hline 1 & 39.7 & 30.2 & $>.05$ & 0 & $>.05$ & 25 & $<.05$ & $<.01$ \\
\hline 2 & 21.6 & 36.4 & & 50 & & 0 & & \\
\hline 3 & 27.0 & 15.2 & & 0 & & 0 & & \\
\hline 4 & 11.7 & 18.2 & & 50 & & 75 & & \\
\hline NICU admission (\%) & 6 & 90 & $<.001$ & 100 & $<.001$ & 100 & $<.001$ & $<.001$ \\
\hline Duration of admission (day) ${ }^{e}$ & $\begin{array}{c}0 \\
(0 \text { to } 6)\end{array}$ & $\begin{array}{c}5 \\
(0 \text { to 13) }\end{array}$ & $<.001$ & $\begin{array}{c}3.5 \\
(0 \text { to } 7)\end{array}$ & $<.001$ & $\begin{array}{c}11 \\
\text { (8 to 22) }\end{array}$ & $<.001$ & $<.001$ \\
\hline$<7.0(\%)$ & 2.3 & 26.3 & $<.001$ & 0 & $>.05$ & 0 & $>.05$ & $<.01$ \\
\hline$<7.1(\%)$ & 6.8 & 36.8 & $<.001$ & 33.3 & $>.05$ & 25.0 & $>.05$ & $<.001$ \\
\hline$<7.2(\%)$ & 25.0 & 63.2 & $<.001$ & 33.3 & $>.05$ & 50.0 & $>.05$ & $<.01$ \\
\hline Cord blood base excess at birthe & $\begin{array}{c}-4.45 \\
(-19.5 \text { to } 15)\end{array}$ & $\begin{array}{c}-10.75 \\
(-3 \text { to }-19.9)\end{array}$ & $<.001$ & $\begin{array}{c}-2.20 \\
(-12.1 \text { to }-1.7)\end{array}$ & $>.05$ & $\begin{array}{c}-6.45 \\
(-15 \text { to }-1)\end{array}$ & $>.05$ & $<.001$ \\
\hline \multicolumn{9}{|l|}{ Intrapartum factor } \\
\hline Fever $\geq 38^{\circ} \mathrm{C}(\%)$ & 35 & 57 & $>.05$ & 66 & $>.05$ & 50 & $>.05$ & $>.05$ \\
\hline Rupture of membranes to delivery (min) & $\begin{array}{c}316 \\
(0 \text { to } 1,400)\end{array}$ & $\begin{array}{c}339.5 \\
(0 \text { to } 1,178)\end{array}$ & $>.05$ & $\begin{array}{c}368 \\
\text { (0 to 472) }\end{array}$ & $>.05$ & $\begin{array}{c}175.5 \\
\text { (0 to 876) }\end{array}$ & $>.05$ & $>.05$ \\
\hline Use of oxytocin (\%) & 72.5 & 75 & $>.05$ & 66 & $>.05$ & 50 & $>.05$ & $>.05$ \\
\hline Use of epidural anesthesia (\%) & 81.4 & 93 & $>.05$ & 66 & $>.05$ & 50 & $>.05$ & $>.05$ \\
\hline Oligohydramnios (\%) & 9 & 9 & $>.05$ & 33 & $>.05$ & 0 & $>.05$ & $>.05$ \\
\hline Fetal tachycardia (\%) & 29 & 60 & $<.05$ & 33 & $>.05$ & 50 & $>.05$ & $<.05$ \\
\hline Fetal bradycardia (\%) & 1 & 0 & $>.05$ & 0 & $>.05$ & 25 & $>.05$ & $>.05$ \\
\hline Minimal fetal heart rate variability (\%) & 46 & 70 & $>.05$ & 33 & $>.05$ & 75 & $>.05$ & $>.05$ \\
\hline
\end{tabular}

MAS, meconium aspiration syndrome; C/S, cesarean section; NICU, neonatal intensive care unit.

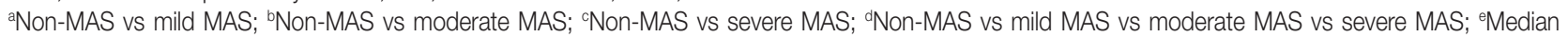
(range). 
response explains the pathogenesis of MAS. ${ }^{19}$ Upregulation of adhesion molecules in the umbilical cord was observed in the presence of funisitis, which was thought to result in increased concentrations of cytokines and soluble adhesion molecules in the fetal circulation. Activation of endothelium may affect not only the umbilical cord but also other fetal organs. ${ }^{25}$ Funisitis is associated with adverse neonatal outcome including an Apgar score $<7$ at 1 minute, small for gestational age and the rate of admission to
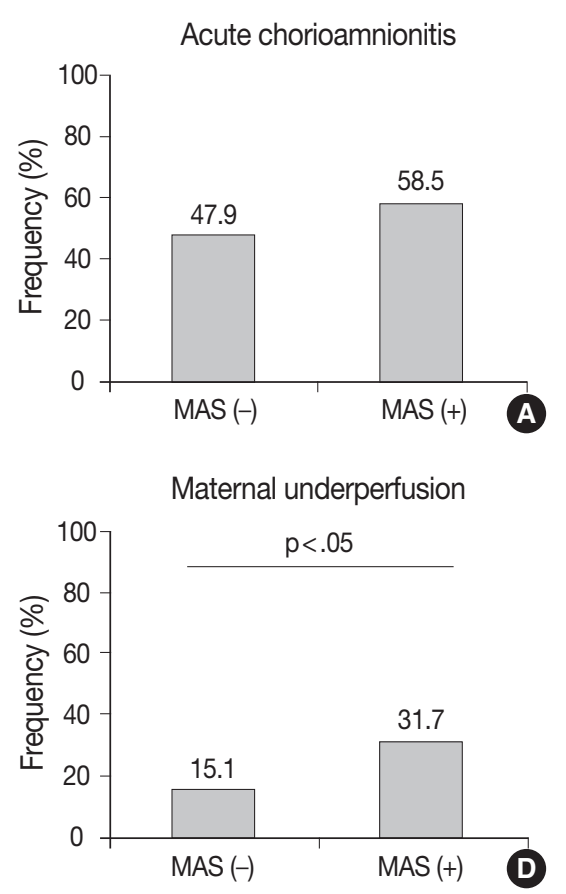

Chronic villitis (VUE)
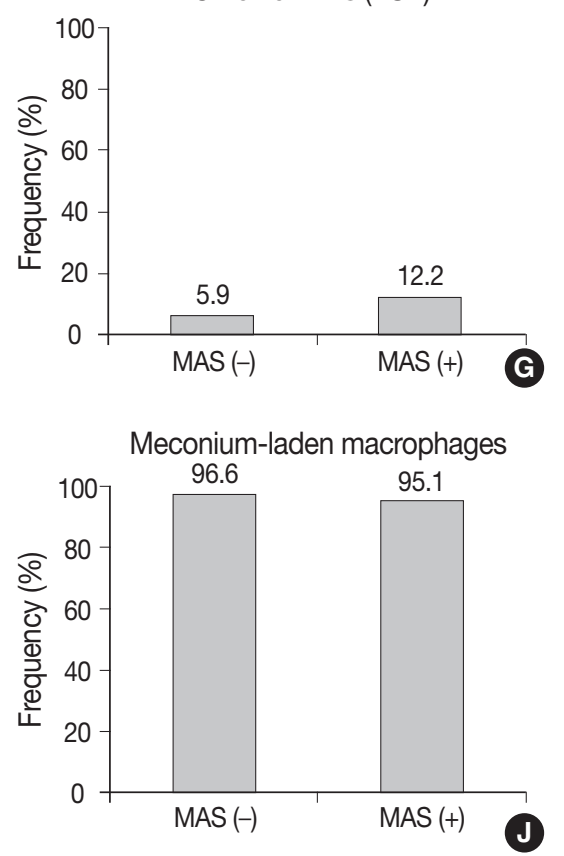

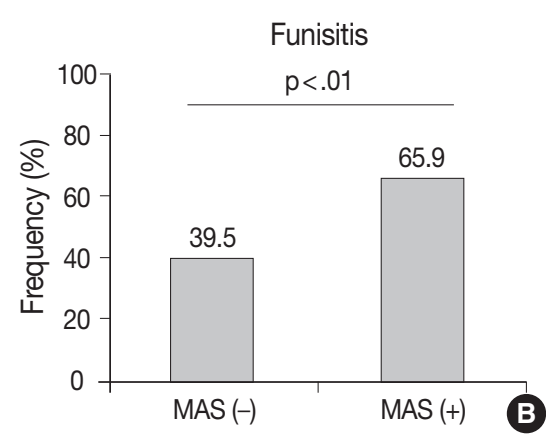

Fetal thrombo-occlusive disease

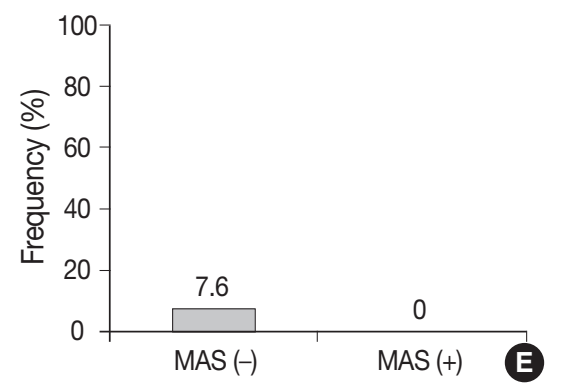

Chronic chorioamnionitis
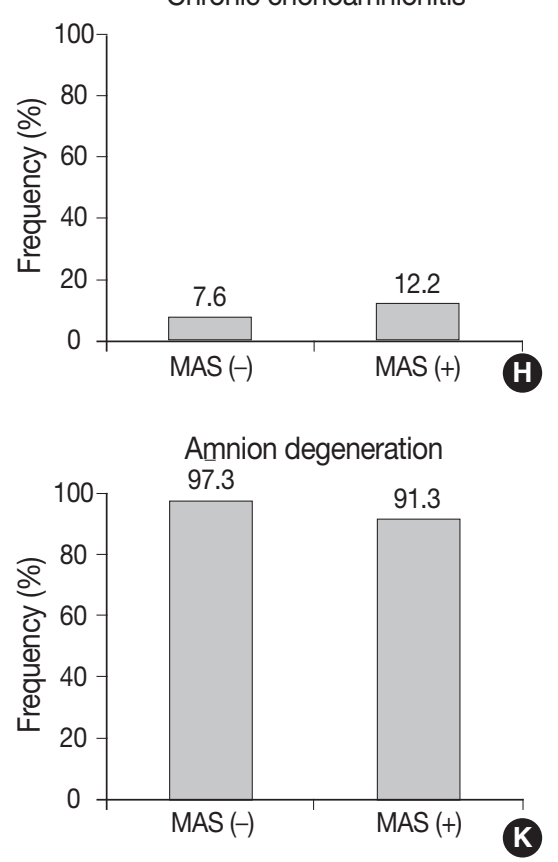

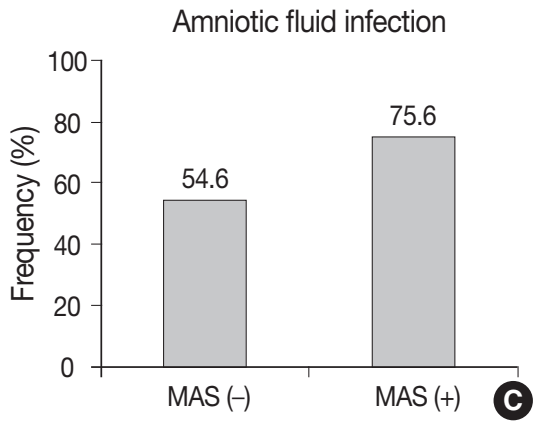

Chronic inflammation
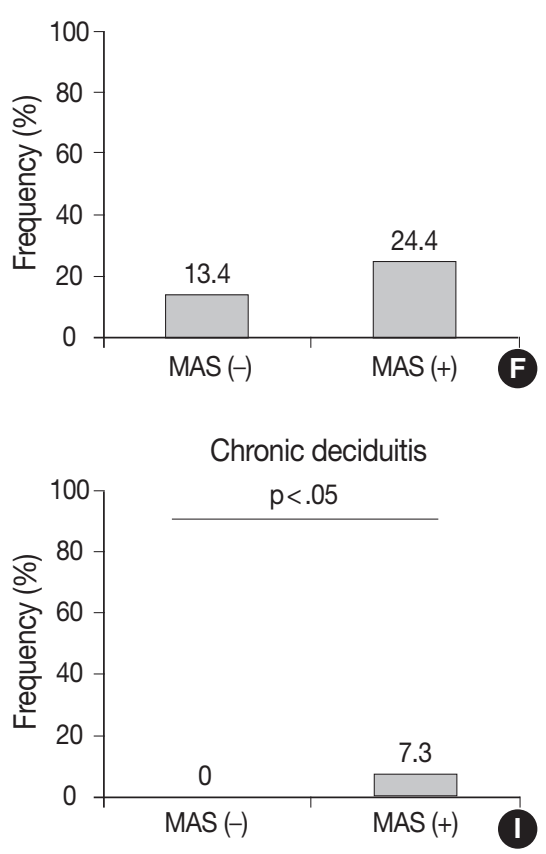

Chorionic vascular muscle necrosis

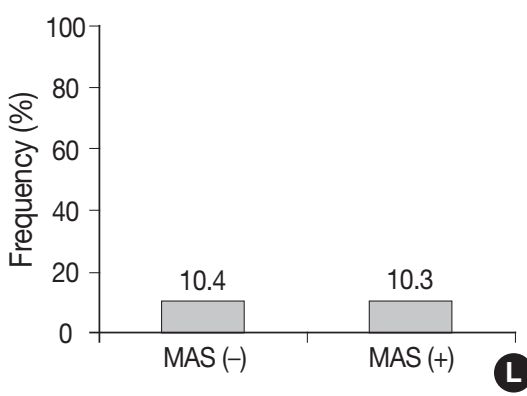

Fig. 2. Comparison of the frequencies of histological findings in the placentas between meconium aspiration syndrome (MAS) and non-MAS placentas. (A) Acute chorioamnionitis. (B) Funisitis. (C) Amniotic fluid infection. (D) Maternal underperfusion. (E) Fetal thrombo-occlusive disease. (F) Chronic inflammation. (G) Chronic villitis. (H) Chronic chorioamnionitis. (I) Chronic deciduitis. (J) Meconium-laden macrophages. (K) Amnion degeneration. (L) Chorionic vascular necrosis. VUE, villitis of unknown etiology. 
the neonatal intensive care unit. It is also related to various clinical diseases such as chronic lung disease, intracranial hemorrhage, cerebral palsy, and negative long-term neurologic outcome. ${ }^{25,35-45}$ The significant relationship of funisitis with MAS was supported by previous studies, but our study is the first to demonstrate the correlation of the severity between funisitis and MAS. ${ }^{19}$

The histological findings associated with maternal underperfusion were identified more frequently in MAS than in non-MAS placentas. Maternal blood from the spiral arteries of the basal plate flows into the intervillous spaces, and the exchange of oxygen and nutrients occurs with fetal blood in the villi. With maternal

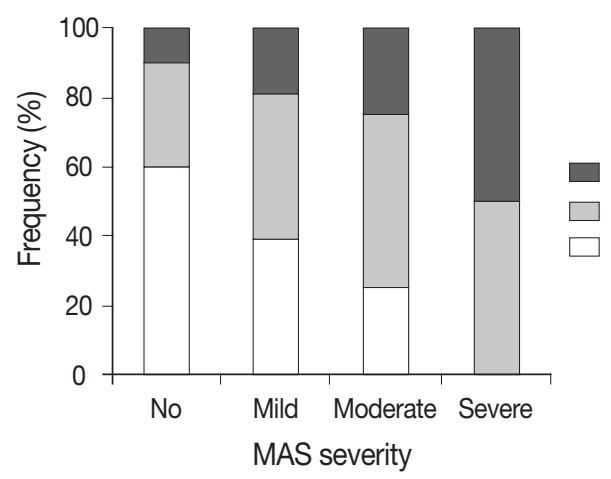

$p<.001$

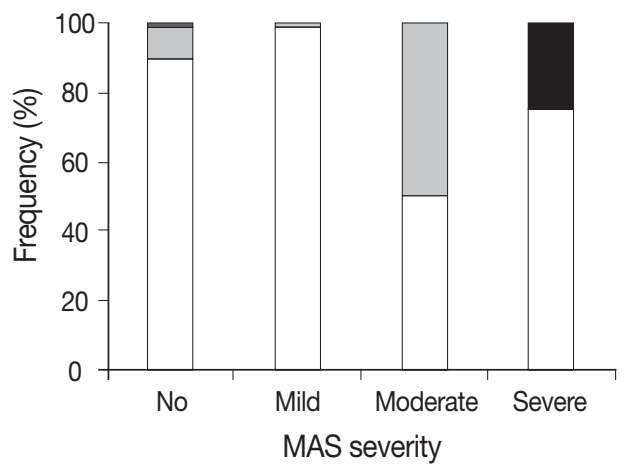

$\mathrm{p}<.05$

- CVMN 3

CVMN 2

$\square$ CVMN 1

$\square$ CVMN 0

B

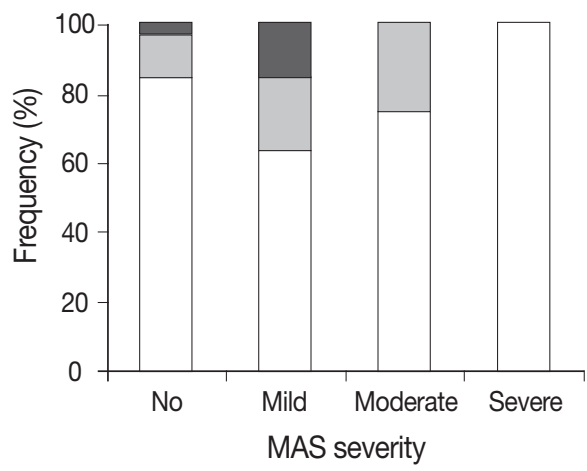

$\mathrm{p}>.05$

MU grade 3

MU grade 2

$\square$ MU grade 1

MU grade 0

Fig. 3. Correlation of the severity of the histological findings in the placentas with the severity of meconium aspiration syndrome (MAS). (A) Funisitis vs MAS. (B) Chorionic vascular muscle necrosis (CVMN) vs MAS. (C) Maternal underperfusion (MU) vs MAS. underperfusion, villi are less perfused, resulting in hypoxic damage and hence increased syncytial knots and villous agglutination. ${ }^{13,46-48}$ Circulatory stasis due to underperfusion also induces intervillous fibrin. ${ }^{13,46,47}$ Long-standing severe hypoxia may result in distal villous hypoplasia, manifested as decreased number, size, and branching. ${ }^{13,49-53}$ Inadequate vascular remodeling and/or structural abnormality of maternal arteries, including mural hypertrophy of arterioles and persistent muscularization of arteries in the basal plate is a known cause of maternal underperfusion such as preeclampsia. ${ }^{13,5458}$ Villous ischemic changes were previously mentioned as a placental finding of MAS, but they were not studied thoroughly. ${ }^{59}$ Maternal underperfusion is a major risk factor of fetal growth restriction, preterm rupture of membrane, and preterm labor. ${ }^{13,60-63}$ Especially, it is frequently related to preeclampsia. ${ }^{13,64}$ Chronic asphyxia is one of the possible causes of MAS. Preeclampsia and maternal hypertension which bring about maternal underperfusion are known as risk factors of MAS. ${ }^{65}$ Because maternal underperfusion can lead to pulmonary hypoplasia and immaturity, this situation is vulnerable to meconium-induced inflammation. Thus, conditions that can cause maternal underperfusion might increase the risk of MAS.

Chronic deciduitis is defined as the presence of lymphocytes and plasma cells in the basal plate of the placenta. ${ }^{21,66} \mathrm{Chronic}$ deciduitis has been associated with preterm labor and is also related to adverse outcomes such as intrauterine growth restriction and fetal death. ${ }^{67,68}$ The etiology of chronic deciduitis is still not clear; however, chronic microbial infection and immune response to fetus antigen are thought to be involved. ${ }^{66}$ The latter is supported by the association between chronic deciduitis and basal villitis, its presence in the placenta of pregnancies by egg donation, and the proximity of the plasma cells to trophoblast cells. ${ }^{66}$ The relationship between chronic deciduitis and MAS has not been described before. An immunological predisposing factor to MAS may be suggested; however, the absence of significant association of MAS with chronic villitis and chronic chorioamnionitis, which are also representative of immune response to fetal antigens, does not support the hypothesis. It requires further studies to clarify.

Chorionic vascular muscle necrosis was frequent in MAS, and the severity was correlated with that of MAS. Chorionic vascular muscle necrosis can be diagnosed by observing eosinophilic cytoplasmic degeneration, nuclear pyknosis, discohesion, and rounding of peripheral vascular smooth muscle cells in vessels, resulting from apoptosis in chorionic vessels by prolonged meconium exposure. ${ }^{69}$ It is associated with placental lesions resulting from hypoxia and poor neonatal outcome, including intrauterine growth restriction, intrauterine fetal demise, and fetal distress. ${ }^{70}$ 
Collectively, our data support that fetal inflammatory response evidenced by funisitis and chorionic vascular muscle necrosis occurs prenatally in MAS. It is unlikely that MAS is simply caused by aspiration of meconium in utero or during the intrapartum period, which is relatively short, because these placental pathologic findings require a certain time period to be raised. Thureen $e t$ al. ${ }^{59}$ reported that MAS is a kind of prenatal disease based on histopathologic pulmonary and placental evidences. Meconium passage normally occurs within the first 24 to 48 hours after birth, especially when the babies are 37 weeks or older. But, it is known to be associated with fetal distress such as hypoxia and infection in near-term or term babies. ${ }^{2}$ There is also a hypothesis that the fetal swallowing of amniotic fluids containing various factors which evoke inflammation can lead to bowel peristalsis and meconium passage. ${ }^{19}$ There are a variety of hypotheses on how meconium raises the respiratory distress in neonates. Nitric oxide $(\mathrm{NO})$ has been known to damage lung epithelial cells responding to meconium. As such, Muller $e t a l^{71}$ found that lipopolysaccharide and meconiuminduced NO production is positively regulated by DMBT1. Ghidini and Spong ${ }^{5}$ suggested that alternative mechanisms, such as chronic asphyxia, infection, and acute asphyxia, cause severe MAS that can result in meconium passage in utero and lung damage. There is a possibility that the above mechanisms are causative of both meconium passage and severe MAS, rather than that the meconium passage would be a direct cause of severe MAS. ${ }^{5}$

The limitations of this study include the followings: first, placentas were not collected consecutively from all births, and the placentas from neonates with MAS were enrolled for pathological examination at a higher rate than those without MAS. This selection bias explains the high frequency of MAS and inconsistent statistics of clinical characteristics in this study compared with those reported previously. ${ }^{1-4,7}$ Second, the relatively small number of moderate and severe MAS cases included may have limited the statistical significance of the results. This is partly supported by that some clinical factors found to be significantly different between mild MAS and non-MAS did not show statistically significant difference between moderate/severe MAS and non-MAS. Further studies with consecutive collection of a larger number of cases could confirm our results and also may find additional placental findings as risk factors.

Our results suggest that fetal inflammatory response evidenced by funisitis occurs prenatally in MAS, and the stage of funisitis and the severity of chorionic vascular muscle necrosis may be predictive markers of the severity of MAS. If meconium staining is detected during delivery and MAS is clinically suspected, the placenta should be fully examined to determine whether these abnormal findings exist and at what stages they are. If the placenta shows high-grade funisitis or extensive chorionic vascular muscle necrosis, the neonate should be treated aggressively from the very beginning to prevent severe MAS.

\section{Conflicts of Interest}

No potential conflict of interest relevant to this article was reported.

\section{Acknowledgments}

This study was supported by the Basic Science Research Program through the National Research Foundation of Korea (NRF) funded by the Ministry of Science, ICT and Future Planning (NRF-2012R1A1A3012668), Republic of Korea.

\section{REFERENCES}

1. Fischer C, Rybakowski C, Ferdynus C, Sagot P, Gouyon JB. A population-based study of meconium aspiration syndrome in neonates born between 37 and 43 weeks of gestation. Int J Pediatr 2012; 2012: 321545.

2. Ahanya SN, Lakshmanan J, Morgan BL, Ross MG. Meconium passage in utero: mechanisms, consequences, and management. Obstet Gynecol Surv 2005; 60: 45-56.

3. Hofmeyr GJ, Xu H. Amnioinfusion for meconium-stained liquor in labour. Cochrane Database Syst Rev 2010; (1): CD000014.

4. Lauzon L, Hodnett E. Labour assessment programs to delay admission to labour wards. Cochrane Database Syst Rev 2001; (3): CD000936.

5. Ghidini A, Spong CY. Severe meconium aspiration syndrome is not caused by aspiration of meconium. Am J Obstet Gynecol 2001; 185: 931-8.

6. Wiswell TE, Bent RC. Meconium staining and the meconium aspiration syndrome. Unresolved issues. Pediatr Clin North Am 1993; 40: $955-81$.

7. Choi W, Jeong H, Choi SJ, et al. Risk factors differentiating mild/ moderate from severe meconium aspiration syndrome in meconiumstained neonates. Obstet Gynecol Sci 2015; 58: 24-31.

8. Hernández C, Little BB, Dax JS, Gilstrap LC 3rd, Rosenfeld CR. Prediction of the severity of meconium aspiration syndrome. Am J Obstet Gynecol 1993; 169: 61-70.

9. Spong CY, Ogundipe OA, Ross MG. Prophylactic amnioinfusion for meconium-stained amniotic fluid. Am J Obstet Gynecol 1994; 171: $931-5$.

10. Cornish JD, Dreyer GL, Snyder GE, et al. Failure of acute perinatal 
asphyxia or meconium aspiration to produce persistent pulmonary hypertension in a neonatal baboon model. Am J Obstet Gynecol 1994; 171: 43-9.

11. Jovanovic R, Nguyen HT. Experimental meconium aspiration in guinea pigs. Obstet Gynecol 1989; 73: 652-6.

12. Redline RW, Faye-Petersen $O$, Heller D, et al. Amniotic infection syndrome: nosology and reproducibility of placental reaction patterns. Pediatr Dev Pathol 2003; 6: 435-48.

13. Redline RW, Boyd T, Campbell V, et al. Maternal vascular underperfusion: nosology and reproducibility of placental reaction patterns. Pediatr Dev Pathol 2004; 7: 237-49.

14. Redline RW, Ariel I, Baergen RN, et al. Fetal vascular obstructive lesions: nosology and reproducibility of placental reaction patterns. Pediatr Dev Pathol 2004; 7: 443-52.

15. Altshuler G, Arizawa M, Molnar-Nadasdy G. Meconium-induced umbilical cord vascular necrosis and ulceration: a potential link between the placenta and poor pregnancy outcome. Obstet Gynecol 1992; 79(5 Pt 1): 760-6.

16. Miller PW, Coen RW, Benirschke K. Dating the time interval from meconium passage to birth. Obstet Gynecol 1985; 66: 459-62.

17. Burgess AM, Hutchins GM. Inflammation of the lungs, umbilical cord and placenta associated with meconium passage in utero: review of 123 autopsied cases. Pathol Res Pract 1996; 192: 1121-8.

18. Espinheira MC, Grilo M, Rocha G, Guedes B, Guimarães H. Meconium aspiration syndrome: the experience of a tertiary center. Rev Port Pneumol 2011; 17: 71-6.

19. Lee J, Romero R, Lee KA, et al. Meconium aspiration syndrome: a role for fetal systemic inflammation. Am J Obstet Gynecol 2016; 214: 366.e1-9.

20. Kim CJ, Romero R, Kusanovic JP, et al. The frequency, clinical significance, and pathological features of chronic chorioamnionitis: a lesion associated with spontaneous preterm birth. Mod Pathol 2010; 23: 1000-11.

21. Khong TY, Bendon RW, Qureshi F, et al. Chronic deciduitis in the placental basal plate: definition and interobserver reliability. Hum Pathol 2000; 31: 292-5.

22. Kim CJ, Romero R, Chaemsaithong P, Chaiyasit N, Yoon BH, Kim YM. Acute chorioamnionitis and funisitis: definition, pathologic features, and clinical significance. Am J Obstet Gynecol 2015; 213(4 Suppl): S29-52.

23. Overbach AM, Daniel SJ, Cassady G. The value of umbilical cord histology in the management of potential perinatal infection. J Pediatr 1970; 76: 22-31.

24. Maudsley RF, Brix GA, Hinton NA, Robertson EM, Bryans AM, Haust MD. Placental inflammation and infection: a prospective bacteriologic and histologic study. Am J Obstet Gynecol 1966; 95:
648-59.

25. D'Alquen D, Kramer BW, Seidenspinner S, et al. Activation of umbilical cord endothelial cells and fetal inflammatory response in preterm infants with chorioamnionitis and funisitis. Pediatr Res 2005; 57: 263-9.

26. Pacora P, Chaiworapongsa T, Maymon E, et al. Funisitis and chorionic vasculitis: the histological counterpart of the fetal inflammatory response syndrome. J Matern Fetal Neonatal Med 2002; 11: 18-25.

27. Naccasha N, Hinson R, Montag A, Ismail M, Bentz L, Mittendorf R. Association between funisitis and elevated interleukin-6 in cord blood. Obstet Gynecol 2001; 97: 220-4.

28. Yoon BH, Romero R, Park JS, et al. The relationship among inflammatory lesions of the umbilical cord (funisitis), umbilical cord plasma interleukin 6 concentration, amniotic fluid infection, and neonatal sepsis. Am J Obstet Gynecol 2000; 183: 1124-9.

29. Romero R, Hanaoka S, Mazor M, et al. Meconium-stained amniotic fluid: a risk factor for microbial invasion of the amniotic cavity. Am J Obstet Gynecol 1991; 164: 859-62.

30. Mazor M, Furman B, Wiznitzer A, Shoham-Vardi I, Cohen J, Ghezzi F. Maternal and perinatal outcome of patients with preterm labor and meconium-stained amniotic fluid. Obstet Gynecol 1995; 86: 830-3.

31. Halliday HL, Hirata T. Perinatal listeriosis: a review of twelve patients. Am J Obstet Gynecol 1979; 133: 405-10.

32. Cassell GH, Davis RO, Waites KB, et al. Isolation of Mycoplasma hominis and Ureaplasma urealyticum from amniotic fluid at 16-20 weeks of gestation: potential effect on outcome of pregnancy. Sex Transm Dis 1983; 10(4 Suppl): 294-302.

33. Mazor M, Froimovich M, Lazer S, Maymon E, Glezerman M. Listeria monocytogenes: the role of transabdominal amniocentesis in febrile patients with preterm labor. Arch Gynecol Obstet 1992; 252: 109-12.

34. Mazor M, Hershkovitz R, Bashiri A, et al. Meconium stained amniotic fluid in preterm delivery is an independent risk factor for perinatal complications. Eur J Obstet Gynecol Reprod Biol 1998; 81: 9-13.

35. Jessop FA, Lees CC, Pathak S, Hook CE, Sebire NJ. Funisitis is associated with adverse neonatal outcome in low-risk unselected deliveries at or near term. Virchows Arch 2016; 468: 503-7.

36. Du H, Liu E, Xu C, Zhao S, Xiang H, Li Z. Prognostic value of funisitis and/or chorionic vasculitis compared to histologic chorioamnionitis in full-term infants. J Matern Fetal Neonatal Med 2017; 30: 169-73.

37. Kim CJ, Yoon BH, Romero R, et al. Umbilical arteritis and phlebitis mark different stages of the fetal inflammatory response. Am J Obstet Gynecol 2001; 185: 496-500.

38. Matsuda T, Nakajima T, Hattori S, et al. Necrotizing funisitis: clinical significance and association with chronic lung disease in premature infants. Am J Obstet Gynecol 1997; 177: 1402-7. 
39. DiSalvo D. The correlation between placental pathology and intraventricular hemorrhage in the preterm infant. The Developmental Epidemiology Network Investigators. Pediatr Res 1998; 43: 15-9.

40. Yoon BH, Romero R, Park JS, et al. Fetal exposure to an intra-amniotic inflammation and the development of cerebral palsy at the age of three years. Am J Obstet Gynecol 2000; 182: 675-81.

41. Leviton A, Paneth N, Reuss ML, et al. Maternal infection, fetal inflammatory response, and brain damage in very low birth weight infants. Developmental Epidemiology Network Investigators. Pediatr Res 1999; 46: 566-75.

42. Mittendorf R, Montag AG, MacMillan W, et al. Components of the systemic fetal inflammatory response syndrome as predictors of impaired neurologic outcomes in children. Am J Obstet Gynecol 2003; 188: 1438-46.

43. Shatrov JG, Birch SC, Lam LT, Quinlivan JA, McIntyre S, Mendz GL. Chorioamnionitis and cerebral palsy: a meta-analysis. Obstet Gynecol 2010; 116(2 Pt 1): 387-92.

44. Watterberg KL, Demers LM, Scott SM, Murphy S. Chorioamnionitis and early lung inflammation in infants in whom bronchopulmonary dysplasia develops. Pediatrics 1996; 97: 210-5.

45. Moscuzza F, Belcari F, Nardini V, et al. Correlation between placental histopathology and fetal/neonatal outcome: chorioamnionitis and funisitis are associated to intraventricular haemorrage and retinopathy of prematurity in preterm newborns. Gynecol Endocrinol 2011; 27: 319-23.

46. Tominaga T, Page EW. Accommodation of the human placenta to hypoxia. Am J Obstet Gynecol 1966; 94: 679-91.

47. Mayhew TM, Barker BL. Villous trophoblast: morphometric perspectives on growth, differentiation, turnover and deposition of fibrintype fibrinoid during gestation. Placenta 2001; 22: 628-38.

48. Huppertz B, Kingdom J, Caniggia I, et al. Hypoxia favours necrotic versus apoptotic shedding of placental syncytiotrophoblast into the maternal circulation. Placenta 2003; 24: 181-90.

49. Jackson MR, Walsh AJ, Morrow RJ, Mullen JB, Lye SJ, Ritchie JW. Reduced placental villous tree elaboration in small-for-gestationalage pregnancies: relationship with umbilical artery Doppler waveforms. Am J Obstet Gynecol 1995; 172(2 Pt 1): 518-25.

50. Karsdorp VH, Dirks BK, van der Linden JC, van Vugt JM, Baak JP, van Geijn HP. Placenta morphology and absent or reversed end diastolic flow velocities in the umbilical artery: a clinical and morphometrical study. Placenta 1996; 17: 393-9.

51. Macara L, Kingdom JC, Kohnen G, Bowman AW, Greer IA, Kaufmann P. Elaboration of stem villous vessels in growth restricted pregnancies with abnormal umbilical artery Doppler waveforms. Br J Obstet Gynaecol 1995; 102: 807-12.

52. Krebs C, Macara LM, Leiser R, Bowman AW, Greer IA, Kingdom
JC. Intrauterine growth restriction with absent end-diastolic flow velocity in the umbilical artery is associated with maldevelopment of the placental terminal villous tree. Am J Obstet Gynecol 1996; 175: $1534-42$

53. Madazli R, Somunkiran A, Calay Z, Ilvan S, Aksu MF. Histomorphology of the placenta and the placental bed of growth restricted foetuses and correlation with the Doppler velocimetries of the uterine and umbilical arteries. Placenta 2003; 24: 510-6.

54. Kaplan C, Lowell DM, Salafia C. College of American Pathologists Conference XIX on the Examination of the Placenta: report of the Working Group on the Definition of Structural Changes Associated with Abnormal Function in the Maternal/Fetal/Placental Unit in the Second and Third Trimesters. Arch Pathol Lab Med 1991; 115: 709-16.

55. Khong TY. The Robertson-Brosens-Dixon hypothesis: evidence for the role of haemochorial placentation in pregnancy success. Br J Obstet Gynaecol 1991; 98: 1195-9.

56. Kliman HJ. Uteroplacental blood flow: the story of decidualization, menstruation, and trophoblast invasion. Am J Pathol 2000; 157: 1759-68.

57. Khong TY, De Wolf F, Robertson WB, Brosens I. Inadequate maternal vascular response to placentation in pregnancies complicated by pre-eclampsia and by small-for-gestational age infants. Br J Obstet Gynaecol 1986; 93: 1049-59.

58. Barth WH Jr, Genest DR, Riley LE, Frigoletto FD Jr, Benacerraf BR, Greene MF. Uterine arcuate artery Doppler and decidual microvascular pathology in pregnancies complicated by type I diabetes mellitus. Ultrasound Obstet Gynecol 1996; 8: 98-103.

59. Thureen PJ, Hall DM, Hoffenberg A, Tyson RW. Fatal meconium aspiration in spite of appropriate perinatal airway management: pulmonary and placental evidence of prenatal disease. Am J Obstet Gynecol 1997; 176: 967-75.

60. De Wolf F, Brosens I, Renaer M. Fetal growth retardation and the maternal arterial supply of the human placenta in the absence of sustained hypertension. Br J Obstet Gynaecol 1980; 87: 678-85.

61. Lackman F, Capewell V, Richardson B, daSilva O, Gagnon R. The risks of spontaneous preterm delivery and perinatal mortality in relation to size at birth according to fetal versus neonatal growth standards. Am J Obstet Gynecol 2001; 184: 946-53.

62. Arias F, Victoria A, Cho K, Kraus F. Placental histology and clinical characteristics of patients with preterm premature rupture of membranes. Obstet Gynecol 1997; 89: 265-71.

63. Naeye RL. Pregnancy hypertension, placental evidences of low uteroplacental blood flow, and spontaneous premature delivery. Hum Pathol 1989; 20: 441-4.

64. Lain KY, Roberts JM. Contemporary concepts of the pathogenesis 
and management of preeclampsia. JAMA 2002; 287: 3183-6.

65. Edmonds P. An introduction to meconium. Midwifery Today Int Midwife 2014; (111): 32-3.

66. Kim CJ, Romero R, Chaemsaithong P, Kim JS. Chronic inflammation of the placenta: definition, classification, pathogenesis, and clinical significance. Am J Obstet Gynecol 2015; 213(4 Suppl): S53-69.

67. Naeye RL. Functionally important disorders of the placenta, umbilical cord, and fetal membranes. Hum Pathol 1987; 18: 680-91.

68. Katzman PJ. Chronic inflammatory lesions of the placenta. Semin Perinatol 2015; 39: 20-6.

69. King EL, Redline RW, Smith SD, Kraus FT, Sadovsky Y, Nelson DM.
Myocytes of chorionic vessels from placentas with meconium-associated vascular necrosis exhibit apoptotic markers. Hum Pathol 2004; 35: 412-7.

70. Cimic A, Baergen RN. Meconium-associated umbilical vascular myonecrosis: correlations with adverse outcome and placental pathology. Pediatr Dev Pathol 2016; 19: 315-9.

71. Müller H, Weiss C, Renner M, Felderhoff-Müser U, Mollenhauer J. DMBT1 promotes basal and meconium-induced nitric oxide production in human lung epithelial cells in vitro. Histochem Cell Biol 2017; 147: 389-97. 